\title{
INCIDENCE AND RISK FACTORS FOR CRYPTOS- PORIDIUM INFECTION AMONG HEMODIALYSIS PATIENTS: RELATION TO SERUM IPTH LEVELS.
}

\author{
By \\ Abdelhameed A Metwali*, Nairmen Nabih ${ }^{\star *}$, Doaa Abdel-Badie \\ Salem $^{\star *}$, Hussein Sheashaa ${ }^{\star \star *}$, Ahmed Donia ${ }^{\star \star *}$, \\ Hala A El-Nahas ${ }^{\star \star}$, Mohamed Adel Bakr***. \\ Trom \\ *Departments of Internal Medicine (Diabetes and Endocrinology Unit), \\ ${ }^{\star *}$ Medical Parasitology, ${ }^{\star * *}$ Urology and Nephrology center, \\ Faculty of Medicine Mansoura University.
}

\begin{abstract}
Background: Patients with chronic kidney disease are suffering from different electrolytes and hormonal changes. The effect of calcium, phosphorus and parathyroid hormone (PTH) levels as risk factors for Cryptosporidium infection have not been studied before.
\end{abstract}

Aim : To estimate the incidence of Cryptosporidium infection among hemodialysis patients and its relation to calcium, phosphorus and iPTH levels.

Patients and Methods : Seventy nine hemodialysis patients attending the hemodialysis Unit at Mansoura Urology and Nephrology Center and Mansoura University Hospital, and 80 apparently healthy controls were recruited in this study. All studied groups were subjected to history taking and clinical examination. Stool samples were examined macroscopically and microscopically and modified Kinyoun's acid fast stain for detection of intestinal coccidian was used. Blood samples were collected for estimation of iPTH, calcium, phosphorous, serum creatinine and plasma urea.

Results : among the 79 hemodialysis patients $49.4 \%$ had intestinal MANSOURA MEDICAL JOURNAL 
parasites. The most prevalent parasite was Cryptosporidium (40.5\%). The duration and efficiency of hemodialysis played a role in the increased incidence of parasitic infection $(P=0.031,0.004$ respectively), iPTH level played additional role $(P=0.002)$. Efficiency of hemdialysis was the most predictor risk factor for intestinal parasitic infection among hemodialysis patients $(\mathrm{OR}=0.19$, $\mathrm{Cl}=0.05-0.82, \mathrm{P}=0$ 0.02).

Conclusions : Cryptosporidium is a common parasitic infection in hemodialysis patients, special stain should routinely used in stool examination for its detection. Improving the efficiency of hemodialysis may help to reduce the incidence of parasitic infections. The iPTH is associated with increased incidence of Cryptosporidium infection and this needs further studies to confirm its role.

Keywords : Hemodialysis, Intestinal parasites, Cryptosporidium, Parathyroid hormone, Phosphorus, Calcium.

\section{INTRODUCTION}

Infection remains one of the major causes of morbidity and mortality among hemodialysis patients.
Emerging intestinal parasites have gained increasing attention as important opportunistic pathogens responsible for clinically significant infections in immunocompromised patients. ${ }^{1}$ Protozoal infections in such patients are common as cryptosporidiosis, isosporiasis, cyclosporiasis, and giardiasis. ${ }^{2}$ Strongyloides stercoralis is a common helminth that cause severe infection among them. ${ }^{3}$

Secondary hyperparathyroidism and hyperphosphatemia are highly prevalent among end stage renal disease (ESRD) patients and have been studied as a possible factor in the development of infection among these patients. ${ }^{4-8}$ However, the evidence about the role of intact parathyroid hormone (iPTH), calcium and phosphorus level in increasing the risk of parasitic infection among them is still conflicting.

Many studies showed increased prevalence of Cryptosporidium infection among maintenance hemodialysis patients 8,14,15,24. The risk factors especially the electrolyte and parathyroid hormone levels that may predispose to this infection have not been studied before, so the aim

Vol. 42, No. 1 \& 2 Jan. \& April, 2013 
of this study is to demonstrate the incidence and risk factors that may predispose to intestinal parasitic infection especially Cryptosporidium among hemodialysis patients.

\section{SUBJECTS AND METHODS}

In this study, 79 hemodialysis patients undergoing maintenance hemodialysis at Urology and Nephrology Center and Mansoura University Hospital. In addition, 80 apparently healthy matched controls not complaining of any chronic diseases e.g. diabetes, liver diseases, malignanc, were recruited in the study. Exclusion criteria involved history of parathyroidectomy and having antiparasitic treatment in the previous six monthes. The protocol met the requirement of the local institutional ethics board and informed consents from all patients prior to the study were done. Participants underwent maintenance HD three times weekly using hollow-fiber dialyzers and bicarbonate dialysates containing calcium and magnesium at concentrations of 2.5 to 3.5 and $1.0 \mathrm{mEq} / \mathrm{L}$, respectively.

All patients were subjected to history taking (age, gender, residence\& duration of hemodialysis) and clinical examination.

Collection and examination of stool samples:

Stool samples were taken from patients in special plastic container and transferred to laboratory at the end of each working day. Stool samples were collected and examined macroscopically for consistency, color, odor, and the presence of blood, mucus, and gross parasites. Stool samples were divided into two parts: One part designated for direct smear and stool culture, direct wet smear was done for detection of helminths or protozoa. The second part was preserved in formalin to be examined by formalin-ether concentration method. 9

Modified acid-fast stain: Smeared slides were prepared, air dried and fixed with absolute methanol for one min, then they were stained with carbol fuchsin for $5 \mathrm{~min}$. After that slides were rinsed briefly (5 seconds) with $50 \%$ ethanol then thoroughly washed with water. The slides were decolorized with $1 \%$ sulfuric acid for $2 \mathrm{~min}$. then rinsed with water and drained. Counter-stain, methylene blue was added to the

MANSOURA MEDICAL JOURNAL 
slides for $1 \mathrm{~min}$. Finally the slides were rinsed with water and left to dry in air. 10

Harada-Mori filter paper strip culture: for detection of Strongyloides stercoralis larvae. ${ }^{11}$

Blood sample collection and examination:

Pre-dialysis blood samples $(5 \mathrm{ml})$ were collected under aseptic condition and the serum was separated. Biochemical testing for estimation of serum creatinine, complete blood count, calcium (reference range 8.8$10.4 \mathrm{mg} / \mathrm{dl}$ ), phosphorous (reference range $2.5-4.3 \mathrm{mg} / \mathrm{dl}$ ) and $\mathrm{iPTH}$ levels were done. Plasma urea level also was estimated. Urea reduction ratio (URR) was calculated to evaluate efficiency of hemodialysis ( $>65 \%$ considered efficient dialysis). ${ }^{12}$ Detection of anti-Strongyloides stercoralis antibodies was done using an ELISA technique (DRG ${ }^{\circledR}$ Strongyloides IgG (EIA-4208) DRG International Inc., USA) for the qualitative screening of serum anti-Strongyloides IgG antibodies. The levels of IPTH were measured by the electro ChemiLuminescence Immuno Assay (ECLIA) method using Roche Elecsys PTH kits (reference range 10-65 $\mathrm{pg} / \mathrm{ml})$.

\section{STATISTICAL ANALYSIS}

Data were analyzed using SPSS version 16 for windows (SPSS, Chicago, IL). Data were presented using mean \pm standard deviation for all quantitative values, median for iPTH, and number of cases (percentage) for categorical variables. Normal distribution of continuous parameters was tested by Kolmogorov-Smirnov test. Categorical variables were analyzed using chi -square or fisher exact test whenever applicable. The significance of differences between continuous variables was determined with independent samples t- test or Mann-Whitney test whenever applicable. Logistic regression analysis was performed to identify independent predictors of intestinal parasitic infection. Statistical significance was determined as $\mathrm{P}$ values $<0.05$.

\section{RESULTS}

The clinical and laboratory characteristics of the hemodialysis patients and controls were summerized in table (1). The mean duration of hemodialysis was $9.2 \pm 6.6$ years. The studied groups were gender, age and residence matched $(P>0.05)$. The median iPTH level among hemodialysis patients was $495 \mathrm{pg} / \mathrm{ml}$, (16.6-7689) (table 1).

Vol. 42, No. 1 \& 2 Jan. \& April, 2013 
Among the 79 hemodialysis patients, $39(49.4 \%)$ had intestinal parasitic infection (Table 2) and mixed parasitic infection was detected in 34 $(43 \%)$. Differences in the percentages of parasitism and mixed infection between the controls and the hemodialysis patients were significant ( $\mathrm{P}<0.05$ in both). The most prevalent parasites were Cryptosporidium (40.5\%), Blastocystis hominis $(27.8 \%)$ and Entamoeba histolytica (24.1\%).

The median iPTH levels among patients with Cryptosporidium infection was significantly higher than those without Cryptosporidium infection $(\mathrm{P}=0.046)$ (table 3$)$.

There were statistically significant difference between hemodialysis patients and controls as regard the phosphorus levels $(P<0.001)$, however there were no significant difference between patients with Cryptosporidium infection and those without $(P>0.05)$ (table 3$)$

Risk factors for intestinal parasitic infections among hemodialysis patient were illustrated in table (4). Intestinal parasitic infection was significantly higher in patients with duration of hemodialysis $>5$ years and URR $<65 \%(P=0.031 \& 0.004$ respectively).

The risk of infection with Cryptosporidium significantly increased with the duration of hemodialysis $>5$ years, URR $<65 \%$ and iPTH level $>$ $65 \mathrm{pg} / \mathrm{ml}$ ( $P=0.008,0.03,0.02$ respectively) (table 5).

When doing multiple logistic regression analysis for risk factors, the URR is the only predictor for intestinal parasitic infection among hemodialysis patients $(P=0.03)$ (table 6). On the other hand none of these risk factors were predictor for Cryptosporidium infection among studied cases $(P>0.05)$. 
124 INCIDENCE AND RISK FACTORS FOR CRYPTOSPORIDIUM etc...

Table 1: Demographic and laboratory characteristics of studied cases.

\begin{tabular}{lllc}
\hline \hline Variables & Patients & Controls & $\mathbf{p}$ \\
& $\mathbf{N}=\mathbf{7 9}$ & $\mathbf{N = 8 0}$ & \\
\hline \hline Gender (Male/Female) & $(42 / 37)$ & $(42 / 38)$ & 0.9 \\
Age (year) & $48.8 \pm 15.1$ & $48.1 \pm 12.6$ & 0.8 \\
Residence (Urban/Rural) & $(40 / 39)$ & $(45 / 34)$ & 0.44 \\
Hemoglobin (gm/d) & $9.8 \pm 1.9$ & $13.4 \pm 1.1$ & $<\mathbf{0 0 1}$ \\
Platelet (count x 10 ${ }^{\mathbf{3}}$ ) & $187.5 \pm 79.3$ & $220.4 \pm 68.7$ & $\mathbf{0 . 0 4}$ \\
Serum calcium (mg/dl) & $8.8 \pm 0.9$ & $9.4 \pm 0.3$ & 0.06 \\
Serum phosphorus (mg/d) & $5.4 \pm 1.5$ & $3.3 \pm 0.5$ & $<\mathbf{0 . 0 0 1}$ \\
PTH (pg/ml) & $495(16.6-7689)$ & $30.5(15-50)$ & $<\mathbf{0 . 0 0 1}$ \\
\hline
\end{tabular}

Values represent (means \pm standard deviation), represented (median 'mximum-minimum'). represented (no (\%)), N: number, PTH: parathyroid hormone, URR: urea reduction ratio.

Table 2: Frequencies of intestinal parasitic infections among studied cases:

\begin{tabular}{lccc}
\hline \hline Variable & Parasitized & Parasitized & p \\
& patients & controls & \\
& No $(\%)$ & No $(\%)$ & \\
\hline \hline Parasitic infection & $39(49.4 \%)$ & $24(30 \%)$ & $\mathbf{0 . 0 1 5}$ \\
Cryptosporidium spp. & $32(40.5 \%)$ & $6(7 \%)$ & $<\mathbf{0 . 0 0 1}$ \\
Blastocystis hominis & $22(27.8 \%)$ & $14(17.5 \%)$ & 0.13 \\
Giardia intestinalis & $9(11.4 \%)$ & $0(0 \%)$ & 0.055 \\
Entamoeba histolytica & $22(27.8 \%)$ & $13(16.3 \%)$ & 0.08 \\
Entamoeba colit & $8(10.1 \%)$ & $0(0 \%)$ & 0.176 \\
Iodamoeba butschlii & $3(3.8 \%)$ & $0(0 \%)$ & 0.553 \\
Enterobius vermicularis egg & $2(2.5 \%)$ & $0(0 \%)$ & 0.9 \\
Anti-Strongyloides antibodies & $4(5.1 \%)$ & $0(0 \%)$ & 0.314 \\
Mixed parasitism & $34(43 \%)$ & $2(2.5 \%)$ & $<\mathbf{0 . 0 0 1}$ \\
\hline \hline
\end{tabular}

N, number

Vol. 42, No. 1 \& 2 Jan. \& April, 2013 
Table (3): Comparison between calcium, phosphorus and iPTH levels among hemodialysis patients with and without Cryptosporidium infections:

\begin{tabular}{|c|c|c|c|}
\hline \multirow[t]{2}{*}{ Variable } & \multicolumn{2}{|c|}{ Patients } & \multirow[b]{2}{*}{$\mathbf{P}$} \\
\hline & $\begin{array}{c}\text { Parasitized } \\
\mathrm{N}=32\end{array}$ & $\begin{array}{c}\text { Non parasitized } \\
\mathrm{N}=47\end{array}$ & \\
\hline \multicolumn{4}{|l|}{ Calcium (mg/dl) } \\
\hline Mean \pm SD & $8.9 \pm$ & $8.7 \pm 0.97$ & 0.4 \\
\hline \multicolumn{4}{|l|}{ Phosphorus (mg/dl) } \\
\hline Mean \pm SD & $5.6 \pm 1.4$ & $5.2 \pm 1.6$ & 0.2 \\
\hline \multicolumn{4}{|l|}{ PTH ( pg/ml) } \\
\hline $\begin{array}{l}\text { Median } \\
\text { (minimum-maximum) }\end{array}$ & $\begin{array}{c}630 \\
(98-3778)\end{array}$ & $\begin{array}{c}297 \\
(16.6-7689)\end{array}$ & $0.046^{*}$ \\
\hline
\end{tabular}


Table 4: Risk factors for intestinal parasitic infections among hemodialysis patient.

\begin{tabular}{|c|c|c|c|}
\hline \multirow[t]{2}{*}{ Variable } & \multicolumn{2}{|c|}{ Patients } & \multirow[b]{2}{*}{$\mathbf{p}$} \\
\hline & $\begin{array}{l}\text { Parasitized } \\
\mathbf{N}=\mathbf{3 9}\end{array}$ & $\begin{array}{l}\text { Non parasitized } \\
\mathrm{N}=\mathbf{4 0}\end{array}$ & \\
\hline \multicolumn{4}{|l|}{ Age } \\
\hline$>50$ year & 23 & 20 & \\
\hline$<50$ year & 19 & 17 & 0.654 \\
\hline \multicolumn{4}{|l|}{ Gender } \\
\hline Male & 22 & 20 & \\
\hline Female & 17 & 20 & 0.654 \\
\hline \multicolumn{4}{|l|}{ Residence } \\
\hline Urban & 18 & 22 & \\
\hline Rural & 21 & 18 & 0.503 \\
\hline \multicolumn{4}{|l|}{ Duration of HD } \\
\hline$<5$ years & 8 & 18 & $\mathbf{0 . 0 3 1}$ \\
\hline$>5$ years & 31 & 22 & \\
\hline \multicolumn{4}{|l|}{ Efficiency of HD } \\
\hline URR $<65 \%$ & 15 & 4 & 0.004 \\
\hline URR $>65 \%$ & 24 & 36 & \\
\hline \multicolumn{4}{|l|}{ Phosphorus } \\
\hline$<2.5 \mathrm{mg} / \mathrm{dl}$ & 0 & 1 & \\
\hline $2.5-4.3 \mathrm{mg} / \mathrm{dl}$ & 5 & 13 & 0.06 \\
\hline$>4.3 \mathrm{mg} / \mathrm{dl}$ & 34 & 26 & \\
\hline \multicolumn{4}{|l|}{ Calcium } \\
\hline$<8.8 \mathrm{mg} / \mathrm{dl}$ & 12 & 18 & \\
\hline $8.8-10.4 \mathrm{mg} / \mathrm{dl}$ & 26 & 19 & 0.194 \\
\hline$>10.4 \mathrm{mg} / \mathrm{dl}$ & 1 & 3 & \\
\hline \multicolumn{4}{|l|}{ PTH } \\
\hline $10-65 \mathrm{pg} / \mathrm{ml}$ & 6 & 1 & \\
\hline$>65 \mathrm{pg} / \mathrm{ml}$ & 34 & 38 & 0.056 \\
\hline \multicolumn{4}{|l|}{ Leukocytic count } \\
\hline$<4000$ & 8 & 6 & 0.211 \\
\hline 4000-11000 & 30 & 23 & \\
\hline$>11000$ & 1 & 2 & \\
\hline
\end{tabular}

$\mathrm{N}$, number ; HD,hemodialysis, PTH;parathyroid hormone.

Vol. 42, No. 1 \& 2 Jan. \& April, 2013 
Table (5): Risk factors of Cryptosporidium infections among heamodialysis patient:

\begin{tabular}{|c|c|c|c|}
\hline \multirow[b]{2}{*}{ Variable } & \multicolumn{2}{|c|}{ Patients } & \multirow[b]{2}{*}{$\mathbf{P}$} \\
\hline & $\begin{array}{l}\text { Parasitized } \\
\mathbf{N}=32\end{array}$ & $\begin{array}{l}\text { Non parasitized } \\
\mathrm{N}=47\end{array}$ & \\
\hline \multicolumn{4}{|l|}{$\overline{\text { Age }}$} \\
\hline$>50$ (years) & 17 & 26 & \\
\hline$<50$ (years) & 15 & 21 & 0.9 \\
\hline \multicolumn{4}{|l|}{ Gender } \\
\hline Male & 18 & 24 & 0.819 \\
\hline Female & 14 & 23 & \\
\hline \multicolumn{4}{|l|}{ Residence } \\
\hline Urban & 12 & 28 & 0.069 \\
\hline Rural & 20 & 19 & \\
\hline \multicolumn{4}{|l|}{ Duration of HD } \\
\hline$<5$ years & 5 & 21 & \\
\hline$>5$ years & 27 & 26 & 0.008 \\
\hline \multicolumn{4}{|l|}{ Efficacy of HD } \\
\hline URR $<65 \%$ & 12 & 7 & 0.03 \\
\hline URR $>65 \%$ & 20 & 40 & \\
\hline \multicolumn{4}{|l|}{ Phosphorus } \\
\hline$<2.5 \mathrm{mg} / \mathrm{dl}$ & 0 & 1 & \\
\hline $2.5-4.3 \mathrm{mg} / \mathrm{dl}$ & 4 & 14 & 0.13 \\
\hline$>4.3 \mathrm{mg} / \mathrm{dl}$ & 28 & 38 & \\
\hline \multicolumn{4}{|l|}{ Calcium } \\
\hline$<8.8 \mathrm{mg} / \mathrm{dl}$ & 9 & 21 & \\
\hline 8.8-10.4 mg/dl & 22 & 23 & 0.21 \\
\hline$>10.4 \mathrm{mg} / \mathrm{dl}$ & 1 & 3 & \\
\hline \multicolumn{4}{|l|}{ РTH } \\
\hline $10-65 \mathrm{pg} / \mathrm{ml}$ & 0 & 8 & \\
\hline$>65 \mathrm{pg} / \mathrm{ml}$ & 32 & 39 & 0.02 \\
\hline \multicolumn{4}{|l|}{ Leukocytic } \\
\hline$<4000$ & 7 & 7 & \\
\hline $4000-11000$ & 24 & 38 & 0.7 \\
\hline$>11000$ & 1 & 2 & \\
\hline
\end{tabular}

N, number ; HD, hemodialysis, URR; urea reduction ratio, PTH;parathyroid hormone. 
INCIDENCE AND RISK FACTORS FOR CRYPTOSPORIDIUM etc...

Table 6: Multiple logistic regression analysis for risk factors of intestinal parasitic among hemodialysi

\begin{tabular}{lccc}
\hline \multicolumn{1}{c}{ Variable } & Odds & $\mathbf{9 5 \%}$ CI & p \\
& ratio & & \\
\hline \hline Gender & 0.73 & $0.25-2.11$ & 0.6 \\
Age (years) & 1.70 & $0.32-1.59$ & 0.4 \\
Duration of dialysis (years) & 2,62 & $0.8-8.57$ & 0.1 \\
Residence & 1.12 & $0.38-3.29$ & 0.8 \\
URR (\%) & 0.19 & $0.05-0.82$ & $\mathbf{0 . 0 3}$ \\
Phosphorus & 2.83 & $0.87-9.2$ & 0.08 \\
Calcium & 1.43 & $0.52-3.91$ & 0.5 \\
Parathyroid hormone & 7.66 & $0,73-80.01$ & 0.08 \\
Leucocytic count & 1.23 & $0.34-4.54$ & 0.8 \\
\hline \hline CI, confidence & & & \\
\hline
\end{tabular}

CI, confidence inte 


\section{DISCUSSION}

Intestinal parasitic infections is one of the major health problems among immunosuppressed patients, however, there is little information about them among hemodialysis patients.13-15 However, the evidence about the role of intact parathyroid hormone ( $\mathrm{PTTH}$ ), calcium and phosphorus level in increasing the risk of parasitic infection among them is still conflicting, so the aim of this work is to estimate the incidence of Cryptosporidium infections among hemodialysis patients and its relation to calcium phosphorus and iPTH levels.

In the present work, intestinal parasitic infections were detected in $49.4 \%$ of hemodialysis patients and in $30 \%$ of controls. Parasitism and polyparasitism were significantly higher in hemodialysis patients than controls. These results were in consistence with Kulik et al.16 On the other hand, our results exceeded the incidence of other studies. ${ }^{17-18}$

The increased incidence of infection may be related to profound immune dysfunction in ESRD patients. 19-21 Immunosuppress patients are very prone to develop en- teric protozoan parasitic infection due to profound cell-mediated defects. ${ }^{22}$ Also, hemodialysis patients may acquire infections through contact with nursing staff, equipments and materials. ${ }^{23}$

In our study, Cryptosporidium infection is the most prevalent intestinal parasite among hemodialysis patients. The same results were obtained by Baqai et al. 24 The same results also, were obtained but with lower prevalence in some studies. $8,14,15,25$ The low incidence of Cryptosporidium in other study, ${ }^{18}$ could be attributed to none performing of a concentration method before staining. The high incidence of Cryptosporidium infection among our hemodialysis patients could be attributed to the fact that cellular immunity plays the major role against Cryptosporidium infection. 26

The median iPTH levels were significantly higher among hemodialysis patients infected with Cryptosporidium, that may be due to the acquired T-lymphocyte dysfunction associated with hyperparathyroidism. 5, 27

Evaluation of the risk factors for parasitic infections among parasi-

MANSOURA MEDICAL JOURNAL 
130 INCIDENCE AND RISK FACTORS FOR CRYPTOSPORIDIUM etc...

tized hemodialysis patients revealed that, the increased duration and low efficiency of the hemodialysis played a role in the increased incidence of infection. This agreed with some studies 17,28 and disagreed with the others. ${ }^{15,25}$ This may be related to hemodialysis treatment per se, including dialysis membrane type and dialysate purity, which appear to play a significant role in the aggravation of the uraemia induced immunedysfunction. 29,30

In our study, increased duration, decreased efficiency of hemodialysis, and hyperparathyroidism were associated with higher incidence of Cryptosporidium Infection.

In our work, the phosphorus levels is higher among hemodialysis patients $(P<0.001)$ and parasitic infections were more frequent among patients with high phosphate levels although it does not reach significant level $(P=0.06)$. This result enforced the study produced by Plantinga et al.8 who reported that infections of any type were more frequent among patients with high phosphate level. Hyperphosphataemia was directly associated with diminished populations of naïve and central memory $T$ lymphocytes and this may, in part, contribute to the acquired impaired immune response of ESRD. ${ }^{31}$ Also phosphate may act purely as a surrogate for the uraemic state, which has also been associated with immune dysfunction. 8,32,33

Efficiency of hemodialysis was the most predictor risk factor for intestinal parasitic infection among our hemodialysis patients $(O R=0.19$, $\mathrm{Cl}=0.05-0.82)$ and this may be related to improvement of immune dysfunction after efficient hemodialysis.

The 4 positive cases for antiStrongyloides antibodies by ELISA were negative by stool culture. Serologic response to $S$. stercoralis is known to cross-react with other parasites and this cross-reactivity resulted in false positive test. 34

This study is limited by the no assessment of immune system and its relation to Cryptosporidium infection among hemodialysis patients.

In conclusion, Cryptosporidium is common parasitic infection in hemodialysis patients, special stain should be included as a routine test in stool examination for its detection. Among 
hemodialysis patients, improving the efficiency of hemodialysis may help to reduce the incidence of parasitic infections. The iPTH is associated with increased incidence of Cryptosporidium infection among them and this need further studies to confirm its role.

Acknowledgment : the authors would like to acknowledge, Professor, Atef el- Shazly, Professor of medical Parasitology for supporting this work.

No conflict of interest.

\section{REFERENCES}

1-Fantry, L. (2002) : Gastrointestinal infections in the immunocompromised host. Curr Opin Gastroenterol.; 18 (1): 34-39.

2-Ferreira, M.S, Borges, A.S. (2002) : Some aspects of protozoan infections in immunocompromised patients- a review. Mem Inst Oswaldo Cruz; 97 (4): 44357.

3-Derouin, F. (2007) : Parasitic infection in immunocom- promised patients. Rev Prat; 57 (2): 167-73.

4-Alexiewicz, J.M., Smogorzewski, M., Fadda, G.Z., Massry, S.G. (1991) : Impaired phagocytosis in dialysis patients: studies on mechanisms. Am J Nephrol; 11: 102-11.

5-Kaneko, T., Osono, E., Hayama, N., Lino, Y., Terashi, A. (1997) : T-cell activation modified by parathyroid hormone (PTH) in patients with end-stage renal disease. Clin Nephrol, ; 48 (6): 353-58.

6-Hauser, A.B,, Stinghen, A.E., Kato, S., Bucharles, S., Aita, C., Yuzawa, Y., Pecoits-Filho, R. (2008) : Characteristics and causes of immune dysfunction related to uremia and dialysis. Perit Dial Int, 28 (3): S183-87.

7-Kelly, C.J. (1994) : T cell function in chronic renal failure and dialysis. Blood Purif; 12 (1): 36-41.

MANSOURA MEDICAL JOURNAL 
INCIDENCE AND RISK FACTORS FOR CRYPTOSPORIDIUM etc...

8-Planting,a L.C., Fink, N.E., Melamed M.L., Briggs, W.A., Powe, N.R., Jaar, B.G. (2008) : Serum phosphate levels and risk of infection in incident dialysis patients. Clin J Am Soc Nephrol, 3 (5): 1398-406.

\section{9-World Health Organization.} (1991) : Basic laboratory methods in medical parasitology; Macmillan/Clays England; 16-17.

10-Garcia, L.S. (2001) : Macroscopic and microscopic examination of fecal specimens. In: Diagnostic Medical Parasitology. 4th edition, ASM Press American Society for Microbiology Press; Washington, DC.: 771-774.

11-Beaver, P.C., Malek, E.A., Little, M.D. (1964) : Development of Spirometra and Paragonimus eggs in HaradaMori cultures. J Parasitol; 50: 664-66.

12-Owen, W.F., Lew, N.L., Liu, Y., Lowrie, E.G., Lazarus, J.M. (1993) : The urea re- duction ratio and serum albumin concentration as predictors of mortality in patients undergoing hemodialysis. N Engl J Med; 329 (14): 1001-6.

13-Chieffi, P.P., Sens, Y.A., Paschoalotti, M.A., Miorin, L.A., Silva, H.G., Jabur, P. (1998) : Infection by Cryptosporidium parvum in renal patients submitted to renal transplant or hemodialysis. Rev Soc Bras Med Trop; 31 (4): 333-37.

14-Turkcapar, N., Kutlay, S., Nergizoglu, G., Atli, T., Duman, N. (2002) : Prevalence of Cryptosporidium infection in hemodialysis patients. Nephron; 90 (3): 344-46.

15-Seyrafian, S., Pestechian, N., Kerdegari, M., Yousefi, H.A., Bastani, B. (2006) : Prevalence rate of Cryptosporidium infection in hemodialysis patients in Iran. Hemodial In; 10(4): 375-79.

16-Kulik, R.A., Falavigna, D.L., Nishi, L., Araujo, S.M. 
(2008) : Blastocystis sp. and other intestinal parasites in hemodialysis patients. Braz J Infect Dis; 12 (4): 338-41.

17-Emami Naeini, A., Shekar,lan, A., Shahidi, S., Azami, M., Hejazi, S.H., Tazhibi, M. (2011) : The prevalence of intestinal parasitic and fungal agents in hemodialysis patients in Isfahan. Journal of Isfahan Medical School; 28 (121): 1655- .67.

18-Baiomy, A.M., Mohamed, K.A., Ghannam, M.A., Shahat, S.A., Al-Saadawy, A.S. (2010) : Opportunistic parasitic infections among immunocompromised Egyptian patients. J Egypt Soc Parasitol; 40 (3): 797-808.

19-Girndt, M., Sester, M., Sester, U., Kaul, H., Köhler, $\mathbf{H}$. (2001) : Molecular aspects of $\mathrm{T}$ - and $\mathrm{B}$-cell function in uremia. Kidney Int; Suppl, 78: S206-11.

20-Pesanti, E.L. (2001) : Immunologic defects and vaccina- tion in patients with chronic renal failure. Infect Dis Clin North Am; 15 (3): 813-32.

21-Lim, W.H., Kireta, S., Leedham, E., Russ, G.R., Coates, P.T. (2007) : Uremia impairs monocyte and monocyte-derived dendritic cell function in hemodialysis patients. Kidney Int; 72: 1138-48.

22-Barsoum, R.S. (2006) : Parasitic infections in transplant recipients. Nat Clin Pract Nephrol; 2 (9): 490-503.

23-Paula, D.H.Gde., Cruz, I. (2004) : Literature review on Risk of infection in intravenous catheter related to the dialysis treatment - OBJN Club Journal. Online Brazilian Journal of Nursing; (OBJN - ISSN 1676-4285), 3 (1).

24-Baqai, R., Anwar, S., Kazmi, S.U. (2005) : Detection of Cryptosporidium in immunosuppressed patients. J Ayub Med Coll Abbottabad; 17 (3): 38-40.

MANSOURA MEDICAL JOURNAL 
25-Seyrafian, S., Pestechian, N., Namdari, N., Kaviani, M., Kerdegari, M., Parvizian, F., Kassaii, L., Eshaghian, A., Nasri, H. (2011) : Prevalence of parasitic infections in Iranian stable hemodialysis patients. Appl Med Inform; 29 (3): 31-36.

26-Borad, A., Ward, H. (2010) : Human immune responses in cryptosporidiosis. Future Microbiol; 5 (3): 507-19.

27-Shasha, M., Kristal, B., Steinberg, O., Shkolnik, T. (1989) : Effect of parathyroidectomy on $\mathrm{T}$ cell functions in patients with primary hyperparathyroidism. Am J Nephrol; 9 (1): 25-29.

28-Hazrati, Tappeh K.H., Gharavi, M.J., Makhdoumi, K., Rahbar, M., Taghizadeh, A. (2006) : Prevalence of Cryptosporidium spp. infection in renal transplant and hemodialysis patients. Iranian J Publ Health; 35 (3): 54-57.

29-Pecoits-Filho, R., Heimbürger,
O., Bárány, P., Suliman, M., Fehrman-Ekholm, I., Lindholm, B., Stenvinkel, P. (2003) : Associations between circulating inflammatory markers and residual renal function in CRF patients. Am J Kidney Dis; 41 (6): 1212-18.

30-Rahmati, M.A., Homel, P., Hoenich, N.A., Levin, R., Kaysen, G.A., Levin, N.W. (2004) : The role of improved water quality on inflammatory markers in patients undergoing regular dialysis. Int J Artif Organs; 27 (8): 723-27.

31-Yoon, J.W., Gollapudi, S., Pahl, M.V., Vaziri, N.D. (2006) : Naïve and central memory T-cell lymphopenia in endstage renal disease. Kidney Int; 70 (2): 371-76.

32-Ganesh, S.K., Stack, A.G., Levin, N.W., HulbertShearon, T., Port, F.K. (2001) : Association of elevated serum $\mathrm{PO}(4), \mathrm{Ca} x$ $\mathrm{PO}(4)$ product, and parathyroid hormone with cardi- 
ac mortality risk in chronic hemodialysis patients. $\mathrm{J}$ Am Soc Nephrol; 12: 213138.

33-Block, G.A., Klassen, P.S., Lazarus, J.M., Ofsthun, N., Lowrie, E.G., Chertow, G.M. (2004) : Mineral metabolism, mortality, and morbidity in maintenan ce hemodialysis. J Am Soc Nephro; I15: 2208-18.

34-Muck, A.E., Pires, M.L., Lammie, P.J. (2003) : Influence of infection with non-filarial helminths on the specificity of serological assays for antifilarial immunoglobulin G4. Trans R Soc Trop Med Hy; 97 (1): 88-90. 
الملحص العربى

\section{نسبة الاصابة وعوامل الخطر كلاصابة بالكربتوسبوريديه فى مرضى الغسيل الكلوى: وعالاقتها بنسبـة هورمون الغدة الجار-درقية فى اللدم.}

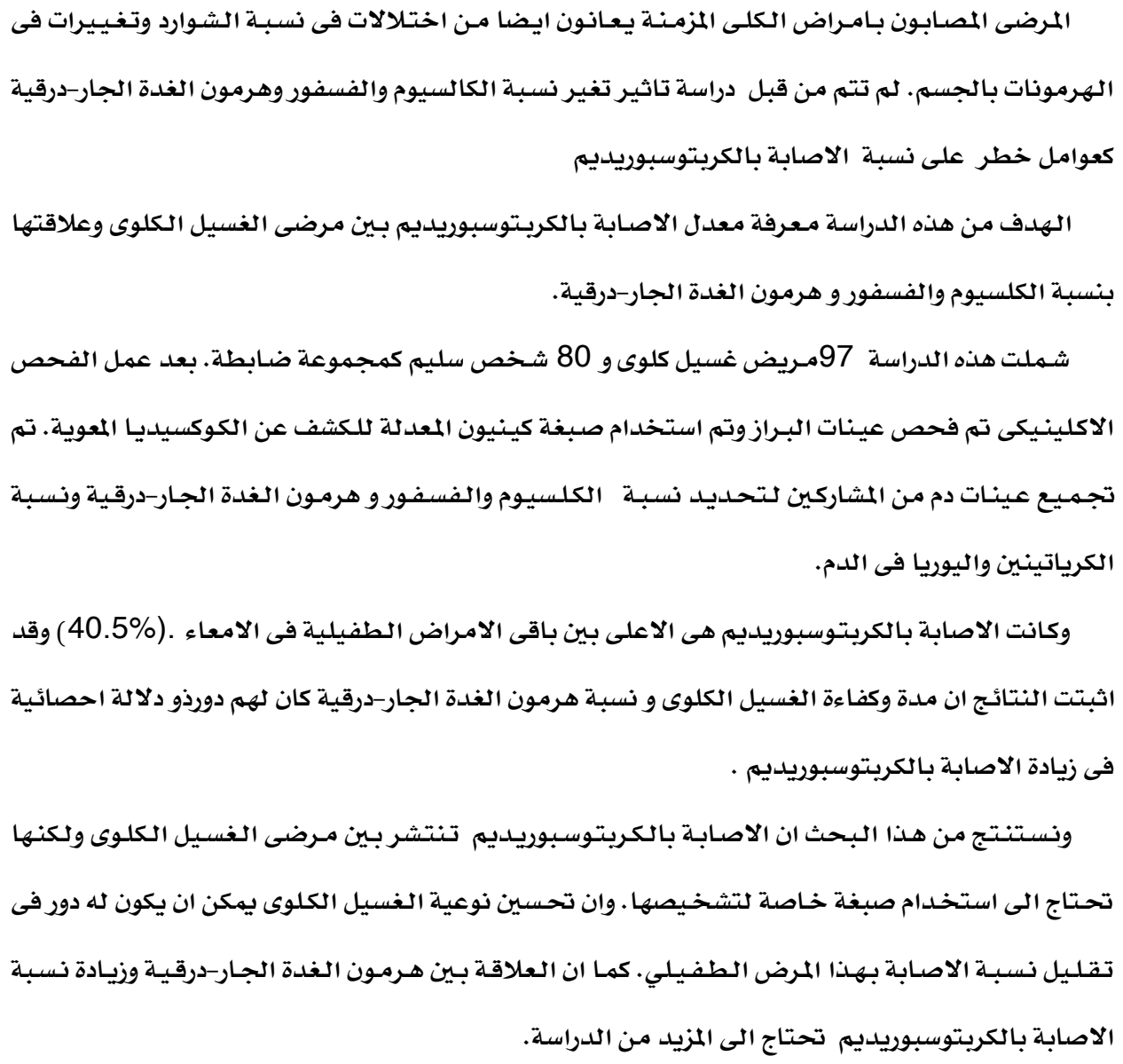

